\title{
Existence of Equilibrium in a Differentiated Duopoly with Network Externalities
}

\author{
Luca Lambertini - Raimondello Orsini \\ Dipartimento di Scienze Economiche \\ Università degli Studi di Bologna \\ Strada Maggiore 45 \\ 40125 Bologna, Italy \\ e-mail lamberti@spbo.unibo.it \\ e-mail orsini@spbo.unibo.it
}

November 13, 1998

\begin{abstract}
The existence of a pure-strategy subgame perfect equilibrium in qualities and prices is investigated in a duopoly model of vertical differentiation where quality improvements require a quadratic variable cost and network externalities appears in consumer utility. Full market coverage is assumed. We show that there always exists a subset of the admissible parameter range where noncooperative profits are non-negative. In such a subset, the incentive to predate prevents firms to reach a pure-strategy noncooperative equilibrium with prices above marginal costs. If network externalities are sufficiently large, a Bertrand equilibrium with zero profits may arise, although the amount of product differentiation is strictly positive. If the weight of network externalities exceeds that of hedonic satisfaction in consumer preferences, then predation is always a dominant strategy.
\end{abstract}

JEL Classification: D62, L13

Keywords: equilibrium existence, vertical differentiation, network externality 


\section{Introduction}

The issue of the existence of a subgame perfect equilibrium in pure strategies has drawn a considerable amount of attention in the existing literature on endogenous product differentiation. When vertical differentiation is considered, technology largely affects the equilibrium market structure. The finiteness property emerges if quality improvements hinge either on fixed costs due to R\&D activity, or upon a variable cost which is not too steep in the quality level (see Gabszewicz and Thisse, 1979, 1980; Shaked and Sutton, 1982, 1983). When variable costs are sufficiently convex, competition obtains as in spatial models à la Hotelling (1929). As stressed by Gabszewicz and Thisse (1986), vertical product differentiation is generally expected to generate pure-strategy equilibria with prices strictly above marginal costs. On the contrary, under horizontal product differentiation, an established result is that a pure-strategy equilibrium in prices may fail to exist (see, inter alia, d'Aspremont et al., 1979; Gabszewicz and Thisse, 1986; Economides, 1986; Anderson, 1988). More precisely, a subgame perfect equilibrium with positive profits may fail to exist, because firms' location choices drive prices to marginal cost. ${ }^{1}$

In several markets, individuals may take their consumption decisions conditially upon the number of other consumers purchasing the same brand or good. This phenomenon is captured by introducing network externalities into consumer preferences. ${ }^{2}$ The presence of network externalities tends to intensify competition. This, in turn, may put into question the existence of a pure strategy equilibrium with positive profits.

We investigate this issue in a duopoly model with vertical differentiation and quadratic costs of quality improvements, where the finiteness property does not hold. We introduce a network externality in consumers' utility function, and investigate the existence and characterization of pure-strategy

\footnotetext{
${ }^{1}$ A price equilibrium in mixed strategies always exists. See Dasgupta and Maskin (1986); Osborne and Pitchik (1987).

${ }^{2}$ Seminal contributions in the theory of network externalities are Katz and Shapiro (1985; 1986); Farrell and Saloner $(1985 ; 1986)$. For an overview, see Katz and Shapiro (1994) and the special issue of the International Journal of Industrial Organization, edited by Economides and Encaoua (1996).
} 
subgame perfect equilibria under full market coverage. We show that there always exists a subset of the parameters measuring hedonic preferences and network externalities, where noncooperative profits are non-negative. In such a subset, the incentive to predate prevents firms to reach a pure-strategy noncooperative equilibrium with prices above marginal costs. Whenever network externalities are large enough, a Bertrand equilibrium with zero profits may arise, although the amount of product differentiation is strictly positive. If the weight of network externalities exceeds that of hedonic satisfaction in consumer preferences, then predation is always a dominant strategy. This prevents firms from reaching a duopoly equilibrium with strictly positive profits.

The remainder of the paper is structured as follows. The model is laid out in section 2. Section 3 describes the market stage. The existence of a pure strategy equilibrium is investigated in section 4 . Concluding remarks are presented in section 5 .

\section{The model}

This setting extends the analysis carried out by several authors (Champsaur and Rochet, 1989; Cremer and Thisse, 1994; Lambertini, 1996; Ecchia and Lambertini, 1997, inter alia). We consider a vertically differentiated duopoly where each firm produces a single good of quality $q$, with $q_{H} \geq q_{L}$, and then competes in prices against the rival. There exists a continuum of consumers indexed by their marginal willingness to pay for quality $\theta \in\left[\theta_{0}, \theta_{1}\right]$, with $\theta_{0}=\theta_{1}-1$. The distribution of consumers is uniform, with density $f(\theta)=1$, so that the population of consumers is 1 . Each consumer buys one unit of the product $i$ that yields the highest net surplus $U=\theta q_{i}+\alpha x_{i}-p_{i}, i=H, L$, where $p_{i}$ is the price of good $i$ and $\alpha \geq 0$ (the same for all agents) is the weight of the network externality in the utility function. We assume that the market is completely covered by firms. Let $\hat{\theta}=\left(\alpha-2 \alpha \theta_{1}+p_{h}-p_{L}\right) /\left(q_{H}-q_{L}-2 \alpha\right)$ define the marginal willingness to pay of the consumer who is indifferent between the high and the low quality good. The market demand functions are, respectively:

$$
x_{H}=\theta_{1}-\hat{\theta}=\theta_{1}-\frac{\alpha-2 \alpha \theta_{1}+p_{h}-p_{L}}{q_{H}-q_{L}-2 \alpha} \text { if } \theta_{1}-\frac{\alpha-2 \alpha \theta_{1}+p_{h}-p_{L}}{q_{H}-q_{L}-2 \alpha} \in(0,1)
$$




$$
\begin{gathered}
x_{H}=1 \text { if } \theta_{1}-\frac{\alpha-2 \alpha \theta_{1}+p_{h}-p_{L}}{q_{H}-q_{L}-2 \alpha} \geq 1 \\
x_{H}=0 \text { if } \theta_{1}-\frac{\alpha-2 \alpha \theta_{1}+p_{h}-p_{L}}{q_{H}-q_{L}-2 \alpha} \leq 0 \\
x_{L}=\hat{\theta}-\theta_{0}=\frac{\alpha-2 \alpha \theta_{1}+p_{h}-p_{L}}{q_{H}-q_{L}-2 \alpha}-\left(\theta_{1}-1\right) \text { if } \frac{\alpha-2 \alpha \theta_{1}+p_{h}-p_{L}}{q_{H}-q_{L}-2 \alpha}-\left(\theta_{1}-1\right) \in(0,1) \\
x_{L}=1 \text { if } \frac{\alpha-2 \alpha \theta_{1}+p_{h}-p_{L}}{q_{H}-q_{L}-2 \alpha}-\left(\theta_{1}-1\right) \geq 1 \\
x_{L}=0 \text { if } \frac{\alpha-2 \alpha \theta_{1}+p_{h}-p_{L}}{q_{H}-q_{L}-2 \alpha}-\left(\theta_{1}-1\right) \leq 0
\end{gathered}
$$

Production technology involves variable costs, which are quadratic in the quality level and linear in the output level:

$$
C_{i}=q_{i}^{2} x_{i} \quad i=H, L,
$$

where $x_{i}$ indicates the output level of firm $i$, whose profit function is

$$
\pi_{i}=\left(p_{i}-q_{i}^{2}\right) x_{i}
$$

The game is fully noncooperative and takes place in two stages. In the first, firms set their respective quality levels; then, in the second, which is the proper market stage, they compete in prices. In both stages, moves are simultaneous. Subgame perfect equilibrium by backward induction is adopted as the solution concept.

\section{The price stage}

Proceeding backwards, we examine first the firms' price behaviour at the market stage, for a generic quality pair. We prove what follows:

Lemma 1 Candidate equilibrium prices decrease as $\alpha$ increases, i.e., $\partial p_{i} / \partial \alpha<$ 0 for all $\alpha>0$.

Proof. From the first order conditions (FOCs henceforth),

$$
\frac{\partial \pi_{H}}{\partial p_{H}}=\frac{p_{L}-2 p_{H}+q_{H}^{2}-\alpha+\theta_{1}\left(q_{H}-q_{L}\right)}{q_{H}-q_{L}-2 \alpha}=0 ;
$$




$$
\frac{\partial \pi_{L}}{\partial p_{L}}=\frac{p_{H}-2 p_{L}+q_{L}^{2}-\alpha+\left(\theta_{1}-1\right)\left(q_{H}-q_{L}\right)}{q_{H}-q_{L}-2 \alpha}=0
$$

the following equilibrium prices obtain:

$p_{H}=\frac{\left(q_{H}-q_{L}\right)\left(\theta_{1}+1\right)+2 q_{H}^{2}+q_{L}^{2}}{3}-\alpha ; \quad p_{L}=\frac{\left(q_{H}-q_{L}\right)\left(2-\theta_{1}\right)+2 q_{L}^{2}+q_{H}^{2}}{3}-\alpha$.

From (7), it can be immediately verified that $\partial p_{i} / \partial \alpha=-1$.

The above result can be given the following interpretation. Although the presence of a network externality component in the utility function rises the reservation price for all consumers as compared to the standard case where $\alpha=0$, the ultimate effect of network externalities is pro-competitive, in that firms are lead to decrease prices in order to enlarge their respective market shares. Fxploiting network externalities so as to increase prices arises if firms collude at the market stage; if instead they do not, as we assume here, then prices are driven towards marginal cost by a standard Bertrand argument based on strategic complementarity. This demand effect may indeed put into question the existence of a pure-strategy subgame perfect equilibrium with prices above marginal costs.

\section{Existence of equilibrium}

Substituting (7) into firms' objective functions and rearranging, we get the profit functions defined exclusively in terms of qualities:

$$
\begin{aligned}
& \pi_{H}\left(q_{H}, q_{L}\right)=\frac{\left[\left(\theta_{1}+1\right)\left(q_{H}-q_{L}\right)-q_{H}^{2}+q_{L}^{2}-3 \alpha\right]^{2}}{9\left(q_{H}-q_{L}-2 \alpha\right)} ; \\
& \pi_{L}\left(q_{H}, q_{L}\right)=\frac{\left[\left(2-\theta_{1}\right)\left(q_{H}-q_{L}\right)+q_{H}^{2}-q_{L}^{2}-3 \alpha\right]^{2}}{9\left(q_{H}-q_{L}-2 \alpha\right)} .
\end{aligned}
$$

Given the symmetry of the model, a quality pair which candidates as the equilibrium of the first stage must be symmetric around $\left(2 \theta_{1}-1\right) / 4$, which is the variety preferred by the average (and median) consumer. Solving the FOCs, we obtain a unique quality pair meeting this requirement:

$$
q_{H}^{*}=\frac{4 \theta_{1}+1}{8} ; \quad q_{L}^{*}=\frac{4 \theta_{1}-5}{8},
$$


which entail the general constraint $\theta_{1} \geq 5 / 4$, in order for $q_{L}$ to be nonnegative. Notice that qualities in (10) coincide with those obtained in the model without network externalities (cf. Cremer and Thisse, 1994; Lambertini, 1996).

The corresponding candidate equilibrium profits are $\pi_{H}^{*}=\pi_{L}^{*}=(3-$ $8 \alpha) / 16$, which are non-negative for all $\alpha \leq 3 / 8$. Market demand is equally split between firms, with $x_{H}=x_{L}=1 / 2$. Observe that the socially optimal qualities would be the first and third quartiles of the interval $\left[\theta_{0} / 2, \theta_{1} / 2\right]$, which obtains from the calculation of the preferred varieties for the richest and the poorest consumer in the market, if such varieties were sold at marginal cost. This implies that (i) qualities are set, respectively, too low and too high as compared to the social optimum; and (ii) this model shares its general features with the model of spatial competition with quadratic transportation costs (see Cremer and Thisse, 1991; 1994).

The pair (10) candidates as the equilibrium of the first stage if two requirements are met. First, profit maximisation requires second order conditions (SOCs):

$$
\frac{\partial^{2} \pi_{H}}{\partial q_{H}^{2}}=\frac{\partial^{2} \pi_{L}}{\partial q_{L}^{2}}=\frac{9-32 \alpha}{6(8 \alpha-3)}<0,
$$

which are met for all $\alpha \in[0,3 / 8)$. The range $\alpha>9 / 32$ is clearly unadmissible. Moreover, the poorest consumer, located at $\theta_{\mathbf{0}}$, must be able to buy, i.e., $\theta_{0} q_{L}+\alpha x_{L}-p_{L} \geq 0$. The necessary and sufficient condition for this to obtain is:

$$
\alpha \geq \frac{16 \theta_{1}\left(1-2 \theta_{1}\right)+9}{96} .
$$

The following questions arise, namely, (i) whether there exists an incentive for firms to modify their respective quality levels so as to steal the market share of the rival, for $\alpha \in[0,3 / 8)$; and (ii) what happens when $\alpha \geq 3 / 8$. In the range $\alpha \in[0,3 / 8)$, the following holds:

Proposition 1 Let $\alpha \geq\left[16 \theta_{1}\left(1-2 \theta_{1}\right)+9\right] / 96$. For all $\alpha \in[0,5 / 24]$, there exists a subgame perfect equilibrium where qualities are $q_{H}^{*}=\left(4 \theta_{1}+1\right) / 8$ and $q_{L}^{*}=\left(4 \theta_{1}-5\right) / 8$. For all $\alpha \in(5 / 24,3 / 8)$, both firms have an incentive to monopolise the market, and no equilibrium exists in pure strategies, where prices are above marginal costs.

Proof. Given the symmetry of the model, we take the high-quality firm's viewpoint. We consider first the case where $q_{L}=q_{L}^{*}$, and investigate the 
incentive for the high-quality producer to manipulate her own quality level in order to predate the rival's market share. Predatory quality is

$$
q_{H}^{P}\left(q_{L}^{*}\right)=\frac{\theta_{1}-2}{2}+\frac{\sqrt{3(3+64 \alpha)}}{8},
$$

at which $x_{H}=1$ and $x_{L}=0$. Observe that

$$
q_{H}^{P}\left(q_{L}^{*}\right)-q_{L}^{*}=\frac{\sqrt{3(3+64 \alpha)}-3}{8},
$$

which reveals that, in the absence of network externalities, predation obtains when the high quality, in the limit, coincides with the low quality. Overall, both (13) and (14) are increasing and concave in $\alpha$. Intuitively, this is due to the fact that, as the weight of network externalities increases, predation is obtained with a comparatively smaller decrease in the high quality, respect to $q_{H}^{*}$. Indeed, we have that

$$
q_{H}^{*}-q_{H}^{P}\left(q_{L}^{*}\right)=\frac{9-\sqrt{3(3+64 \alpha)}}{8},
$$

which is positive and decreasing for all $\alpha \in[0,3 / 8)$. The predatory monopoly profits at $q_{H}^{P}\left(q_{L}^{*}\right)$ amount to $\pi_{H}^{P}=[\sqrt{3(3+64 \alpha)}-(3+16 \alpha)] / 8>0$ for all $\alpha \in[0,3 / 8)$. The incentive towards predation is measured by $\pi_{H}^{P}-\pi_{H}^{*}$, which is positive for all $\alpha \in(5 / 24,3 / 8)$.

The analysis carried out in the above proof is illustrated in figure 1 over the parameter space $\left\{\theta_{1}, \alpha\right\}$. Within the region ABCD, the market is not affluent enough to allow for full market coverage to obtain; to the right of $\alpha=$ $\left(-16 \theta_{1}^{2}+32 \theta_{1}+9\right) / 96$, producing the Nash equilibrium quantity dominates predating, for all $\alpha \in[0,5 / 24)$, and conversely for all $\alpha \in(5 / 24,3 / 8)$. If $\alpha=5 / 24$, firms are indifferent between producing $q_{i}^{*}$ or $q_{i}^{P}\left(q_{j}^{*}\right)$, and it can be assumed that they play the Nash equilibrium. 
Figure 1: Equilibrium analysis

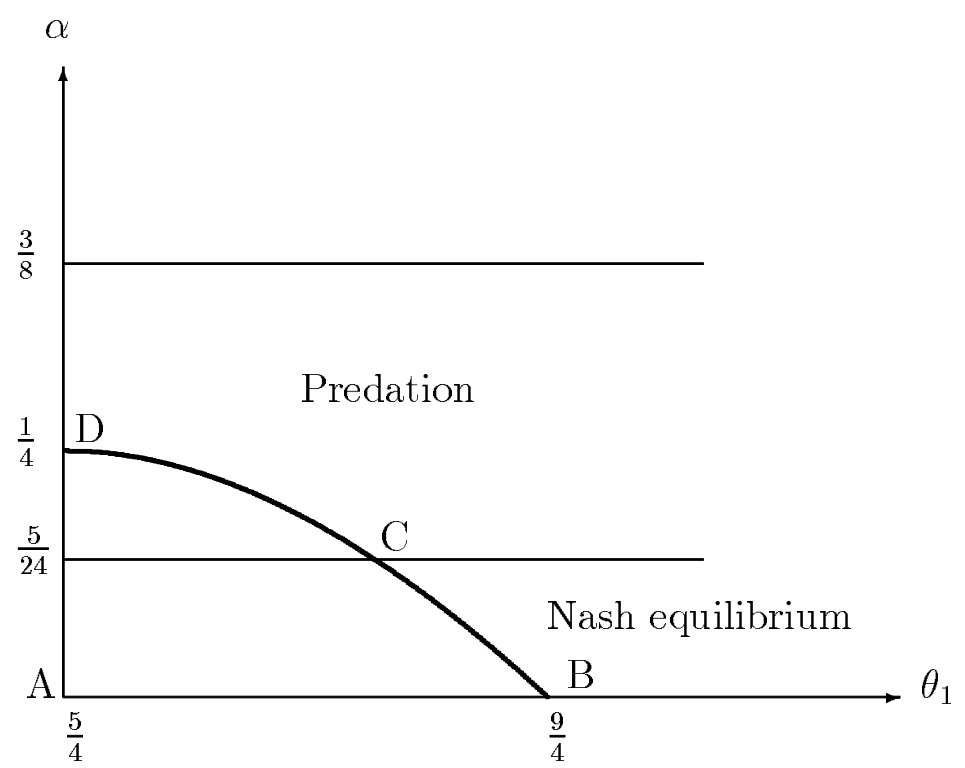

We are now in a position to investigate what happens when $\alpha \geq 3 / 8$. We prove what follows:

Proposition 2 Let $\alpha \geq\left[4 \theta_{1}\left(1-\theta_{1}\right)+16 k^{2}+16 k-1\right] / 24$. For all $\alpha \geq 3 / 8$, firms can gain non-negative profits by producing $q_{H}=\left(2 \theta_{1}-1\right) / 4+k$ and $q_{L}=\left(2 \theta_{1}-1\right) / 4-k$, with $k \geq \alpha$. For any such quality pair, the incentive to predate exists for all $\alpha \in((1-k) / 3, k)$, when $k<1$; and it exists for all $\alpha \in(0, k)$, when $k \geq 1$.

Proof. First of all, if qualities are (10), profits $\pi_{i}^{*}=(3-8 \alpha) / 16$ are negative, so that firms find it preferable not to produce at all. What they can do is to supply an alternative pair of products such that (i) $\left(q_{H}+q_{L}\right) / 2=\left(2 \theta_{1}-1\right) / 4$, i.e. qualities are symmetrically located, respectively, to the left and to the right of the variety preferred by the average (and median) consumer; and (ii) profits are non-negative. To illustrate this issue, suppose that indeed $q_{L}=\left(2 \theta_{1}-1\right) / 2-q_{H}$. The profit function of the high-quality firm simplifies to $\pi_{H}=\left(1-4 \alpha-2 \theta_{1}+4 q_{H}\right) / 8$, which is positive for all $q_{H}>\left(2 \theta_{1}+4 \alpha-1\right) / 4$. The latter condition conveys the relevant information that $q_{H}$ must increase as $\alpha$ increases, and conversely. The intuition behind this fact is that an 
increase in $\alpha$ entails, as we know from lemma 1, a decrease in price, which must be compensated by an increase in product differentiation. ${ }^{3}$

As a result, when $\alpha>3 / 8$, firms adopt a corner (symmetric) solution in qualities with $q_{H}>q_{H}^{*}, q_{L}<q_{L}^{*}$ and $q_{L}=\left(2 \theta_{1}-1\right) / 2-q_{H}$. It is possible to derive a predatory quality $q_{H}^{P}$ for a generic level of $q_{L}$ :

$$
q_{H}^{P}\left(q_{L}\right)=\frac{\theta_{1}-2+\sqrt{4\left(1+3 \alpha-\theta_{1}\right)+\theta_{1}^{2}+8 q_{L}-4 \theta_{1} q_{L}+4 q_{L}^{2}}}{2} .
$$

Suppose, at the candidate equilibrium, $q_{L}=\left(2 \theta_{1}-1\right) / 4-k$ and $q_{H}=$ $\left(2 \theta_{1}-1\right) / 4+k$. The consumer located at $\theta_{0}=\theta_{1}-1$ is able to buy if and only if $\alpha \geq\left[4 \theta_{1}\left(1-\theta_{1}\right)+16 k^{2}+16 k-1\right] / 24$.

Moreover, $q_{H}^{P}\left(q_{L}\right)$ becomes:

$$
q_{H}^{P}\left(q_{L}\right)=\frac{\theta_{1}-2+\sqrt{4 k^{2}-6 k+12 \alpha+9 / 4}}{2} .
$$

Plugging this expression into the high-quality firm's profit function, we get the corresponding predatory profits:

$$
\pi_{H}^{P}=\frac{\sqrt{16 k^{2}-24 k+48 \alpha+9}-3}{4}+k-2 \alpha .
$$

The above predatory quality has to be evaluated against the candidate equilibrium profits that the high-quality firm can get at $q_{H}=\left(2 \theta_{1}-1\right) / 4+k$, amounting to $\hat{\pi}_{H}=(k-\alpha) / 2$. The incentive to predate is measured by:

$$
\pi_{H}^{P}-\hat{\pi}_{H}=\frac{\sqrt{16 k^{2}-24 k+48 \alpha+9}-3-6 \alpha+2 k}{4}
$$

which is positive for all $\alpha \in((1-k) / 3, k)$. Obviously, the lower bound becomes zero for all $k \geq 1$. Finally, observe that, if $k=3 / 8$, this interval becomes $(5 / 24,3 / 8)$.

The above propositions have the following relevant corollaries:

\footnotetext{
${ }^{3}$ To verify that this is indeed the case, observe that, if qualities are $q_{L}=\theta_{0} / 2$ and $q_{H}=\theta_{1} / 2$, i.e., the varieties preferred by the poorest and richest consumer, respectively, then profits amount to $\pi_{H}=\pi_{L}=(1-4 \alpha) / 8$, which are positive for all $\alpha \in[0,1 / 4)$.
} 
Corollary 1 A Nash equilibrium in qualities with prices above marginal production costs exists if and only if the weight attached to market demand does not exceed the weight attached to the hedonic component in the utility function.

Proof. The hedonic component is $\theta q_{i}$. When $\alpha>1$, the externality becomes more important than the intrinsic satisfaction that a consumer derives from the purchase of $q_{i}$. To prove the corollary, it suffices to observe that, whenever $\alpha>1$, the condition $k>\alpha$ entails that predation is always a dominant strategy, as we know from proposition 2.

Corollary 2 For any positive $\alpha$, there exists a Nash equilibrium at the quality stage where the Bertrand paradox with zero profits obtains, even if firms are supplying strictly differentiated goods.

Proof. When $q_{L}=\left(2 \theta_{1}-1\right) / 4-\alpha$ and $q_{H}=\left(2 \theta_{1}-1\right) / 4+\alpha, \pi_{i}^{P}=\hat{\pi}_{i}=0$. Hence, the incentive to predate disappears, and such quality pair is indeed admissible as an equilibrium. However, the equilibrium profits are nil for both firms, notwithstanding the fact that the market is supplied with a strictly positive degree of product differentiation.

The shape of the profit function of the high-quality firm is illustrated in figure 2. A symmetric picture would describe the behaviour of the low-quality firm's profits. 
Figure 2 : The high-quality firm's profit function

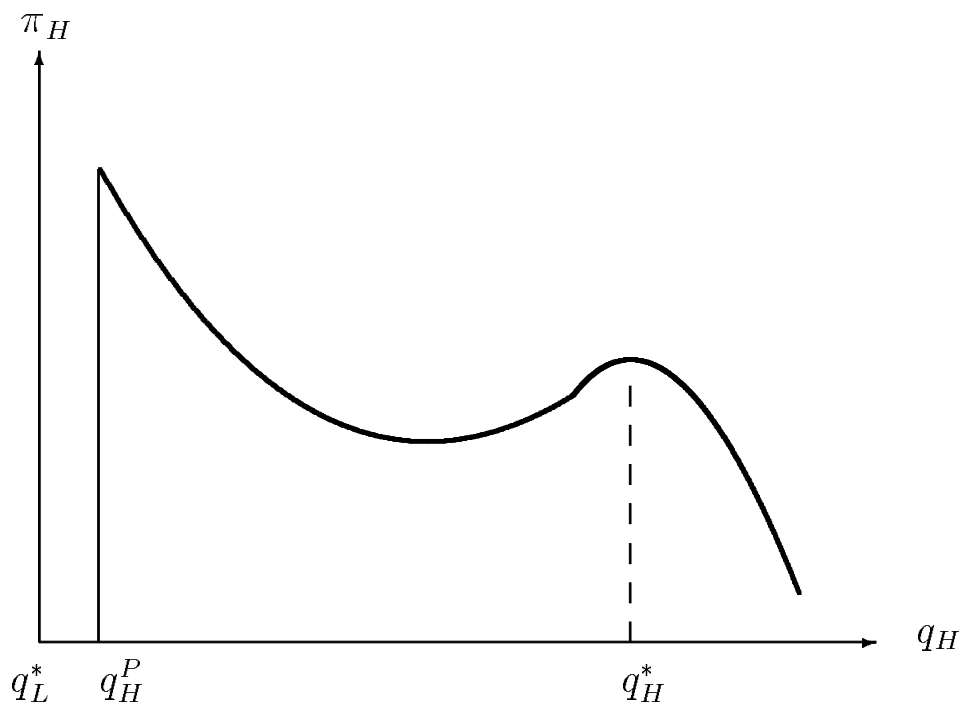

It is known that, under full market coverage, the spatial duopoly model with quadratic transportation costs (d'Aspremont et al., 1979) is a special case of a vertical differentiation model with quadratic costs of quality improvement (Cremer and Thisse, 1991). As a consequence, the above results must hold as well in the horizontal setting with convex disutility of transportation.

\section{Concluding remarks}

In the foregoing analysis, we have investigated the existence of a pure-strategy subgame perfect equilibrium in a vertically differentiated duopoly with convex variable costs of quality and a network externality component in consumers' utility function. We have proved that there exists a subset of the admissible parameter range where noncooperative profits are non-negative. In such a subset, the incentive to predate undermines the existence of a noncooperative equilibrium in pure strategies, with prices above marginal costs. If network externalities are above a critical threshold, equilibrium profits are 
nil notwithstanding that products are differentiated. If the weight of network externalities exceeds that of the hedonic component, then predation is profitable in the whole admissible parameter space; hence, in this case the duopoly equilibrium never exists. The same results hold in the spatial differentiation model with quadratic transportation costs.

The above findings shed some new light on the vexata quaestio of existence and stability of equilibrium in market models with endogenous differentiation. It appears that assuming convex disutility of transportation or, as in the model we use here, convex production costs, is not sufficient to guarantee the existence of equilibrium, in that a relatively small amount of network externality suffices to destroy it. The more detailedly we try to describe market interaction, the more delicate the issues of existence and stability seem to become. 


\section{References}

[1] Anderson, S.P. (1988), "Equilibrium Fxistence in the Linear Model of Spatial Competition", Economica, 55, 479-91.

[2] Champsaur, P. and J.-C. Rochet (1989), "Multiproduct Duopolists", Econometrica, 57, 533-57.

[3] Cremer, H. and J.-F. Thisse (1991), "Location Models of Horizontal Differentiation: A Special Case of Vertical Differentiation Models", Journal of Industrial Economics, 39, 383-90.

[4] Cremer, H. and J.-F. Thisse (1994), "Commodity Taxation in a Differentiated Oligopoly", International Economic Review, 35, 613-33.

[5] Dasgupta, P. and E. Maskin (1986), "The Existence of Equilibrium in Discontinuous Economic Games, II: Applications", Review of Economic Studies, 53, 27-42.

[6] d'Aspremont, C., J.J. Gabszewicz and J.-F. Thisse (1979), "On Hotelling's 'Stability in Competition"', Econometrica, 47, 1145-50.

[7] Ecchia, G. and L. Lambertini (1997), "Minimum Quality Standards and Collusion", Journal of Industrial Economics, 45, 101-13.

[8] Economides, N. (1986), "Minimal and Maximal Differentiation in Hotelling's Duopoly", Economics Letters, 21, 67-71.

[9] Economides, N. and D. Encaoua (1996, eds.), Special Issue on Network Economics: Business Conduct and Market Structure, International Journal of Industrial Organization, 14.

[10] Farrell, J. and G. Saloner (1985), "Standardization, Compatibility and Innovation", RAND Journal of Economics, 16, 70-83.

[11] Farrell, J. and G. Saloner (1986), "Standardization and Variety", Economics Letters, 20, 71-74. 
[12] Gabszewicz, J.J. and J.-F. Thisse (1979), "Price Competition, Quality and Income Disparities", Journal of Economic Theory, 20, 340-59.

[13] Gabszewicz, J.J. and J.-F. Thisse (1980), "Entry (and Exit) in a Differentiated Industry", Journal of Economic Theory, 22, 327-38.

[14] Gabszewicz, J.J. and J.-F. Thisse (1986), "On the Nature of Competition with Differentiated Products", Economic Journal, 96, 160-72.

[15] Hotelling, H. (1929), "Stability in Competition", Economic Journal, 39, $41-57$.

[16] Katz, M. and C. Shapiro (1985), "Network Fxternalities, Competition, and Compatibility", American Economic Review, 75, 424-40.

[17] Katz, M. and C. Shapiro (1986), "Technology Adoption in the Presence of Network Effects", Journal of Political Economy, 94, 822-41.

[18] Katz, M. and C. Shapiro (1994), "Systems Competition and Network Effects", Journal of Economic Perspectives, 8, 93-115.

[19] Lambertini, L. (1996), "Choosing Roles in a Duopoly for Endogenously Differentiated Products", Australian Economic Papers, 35, 205-24.

[20] Osborne, M.J. and C. Pitchik (1987), "Equilibrium in Hotelling"s Model of Spatial Competition", Econometrica, 55, 911-22.

[21] Shaked, A. and J. Sutton (1982), "Relaxing Price Competition through Product Differentiation", Review of Economic Studies, 69, 3-13.

[22] Shaked, A. and J. Sutton (1983), "Natural Oligopolies", Econometrica, $\mathbf{5 1}, 1469-83$. 